\title{
ARTICLE
}

\section{Ethics in science and environmental politics: issues for interdisciplinary teams}

\author{
John Cairns, Jr.* \\ Department of Biology, 1020 Derring Hall, Virginia Polytechnic Institute and State University, Blacksburg, \\ Virginia 24061, USA
}

\begin{abstract}
The quest for sustainable use of the planet will require evidence, analysis and judgment from a wide array of disciplines. In order to produce a systematic and orderly analysis of this information, a synthesis will be essential. This synthesis will be generated most effectively if the individuals designing the research and providing the data interact in a variety of ways. Disciplines are isolated from each other and not accustomed to working together; however, this isolation is changing rapidly. Still, there are many issues not yet satisfactorily resolved. This manuscript illustrates these issues and makes suggestions for improving the situation.
\end{abstract}

KEY WORDS: Interdisciplinary ethics $\cdot$ Consilience $\cdot$ Academic hierarchy $\cdot$ Sustainability

When one tugs at a single thing in nature, he finds it attached to the rest of the world.

$$
\text { —John Muir }
$$

\section{MAJOR WORLD PROBLEMS TRANSCEND THE CAPABILITIES OF A SINGLE DISCIPLINE}

Sustainable use of the planet will require input from a large, diverse array of disciplines (Cairns 1997). Academic and other institutions are not yet prepared for this enormous task, and human society has not confronted, in a substantive way, the ethical issues involved. Interdisciplinary teams and multidimensional people are essential for both. As a caveat, disciplines are essential as quality control units for data, information, methodology, procedures, and personnel. Since funding will increasingly target problems that transcend the capabilities of one discipline,

*E-mail: jcairns@vt.edu entrepreneurial institutions (including academic) must develop appropriate capabilities if they wish to remain competitive.

\section{ENVIRONMENTAL POLITICS}

World-class interdisciplinary teams will not be as effective as they need to be if policymakers and the general public cannot understand their message or deny its importance. Two current situations illustrate this point. Murphy $(2001 \mathrm{a}, \mathrm{b})$ discusses the marketing of illegal or uncontrolled harvest of trees to produce plywood, doors, etc. These products are sold by the world's three largest buyers of lumber who vow to buy 'green'. However, in the global marketplace, ethical intentions are difficult to implement.

The second illustrative case is the opposition in the United States to the modest (e.g., US\$5) 'user fees' the federal government asks visitors to pay at a number of outdoor sites whose use was previously free of charge. Civil disobedience is one of the manifestations of this 
resistance, even though federal officials need the money in the face of stagnant budgets and rising recreational use. Lost in the debate is society's ethical obligation to protect the ecological integrity of the systems being used. Increased use requires increased management, and overuse will damage the very qualities visitors are trying to experience.

Debate is essential in both cases; however, it should focus on human behaviors that will permit sustainable use of both systems. Not to be ignored is society's ethical responsibility for other life forms and the quality of life for human descendants.

\section{ETHICS IN A SUSTAINABILITY CONTEXT}

Arguably, the most important role of interdisciplinary teams is to assure that their studies are congruent with sustainable use of the planet. In order to succeed in this undertaking, an ethos or set of guiding values must be widely accepted. Anything less will not be adequate at the planetary level. This undertaking is, at best, monumental and, at worst, a naive vision in an era of individualism and religious, ethnic, and political rancor. The quest for sustainable use of the planet would not stand a chance if the alternatives were not so appalling.

Within the context of sustainability, three primary ethical considerations arise: (1) human society's relationship with the biospheric life support system; (2) leaving a habitable planet for future generations; and (3) resource use and distribution both among humans and with other species on the planet. These considerations inevitably lead to a large number of ethical issues, illustrated by the following. (a) What percentage of the planet's land area should be allocated to humans and their artifacts and what percentage to the 30+ million other species? (b) How can humans achieve a quality life while substantially reducing the size of both individual and national ecological footprints (details in Wackernagel \& Rees 1996)? (c) What is the justification for not balancing the rate of ecological destruction and repair (e.g., Cairns 1999b)? (d) What is the justification for continuing subsidies that result in environmental degradation (Myers with Kent 1998)? (e) At what rate should natural capital be accumulated (Hawken et al. 1999)? (f) Can the ethical value system adjust with sufficient rapidity to the rate, scale, and subtlety of the environmental transformations of the past century (McNeill 2000)? (g) Can interdisciplinary teams achieve the unity of knowledge essential to sustainable use of the planet (Wilson 1998)? (h) Will the process that produced the human species continue a cultural evolution and produce human natures compatible with sustainable use of the planet
(Ehrlich 2000)? (i) What precautions are justified when human society may be approaching planetary ecological thresholds such as global warming (Raffensperger \& Tickner 1999, Lemons 1996)? (j) Is the quest for sustainability a denial of the reality that nature is unlikely to favor any one species for the life of the planet?

\section{IS THE QUEST FOR SUSTAINABILITY A DENIAL OF REALITY?}

There is no robust evidence that humans can live sustainably on the planet, although some hunter/gatherers appear to have come close. As McNeill (2000) notes, the Chinese may have moved from one set of unsustainable practices to another over a period of thousands of years. Substantial demographic shifts are now occurring and may worsen. Unrestrained burning of fossil fuels will almost certainly cause climate changes of great ecological significance. Impoverishment of species diversity is already being termed the 'sixth great extinction', and there are severe pressures on the freshwater supply (e.g., Committee on Sustainable Water Supplies for the Middle East 1999).

Clearly, multidimensional studies are essential to a systematic and orderly solution to complex, multivariate problems. Unfortunately, however, interdisciplinary teams are often formed to carry out further studies in order to delay implementing remedial measures. In general, postponing remedial action can severely exacerbate an already troublesome situation. As a consequence, the charge to the team (i.e., academic contract) should clearly state the justification for postponing remedial action ('More research is needed' is not adequate) and how the new information will be used and when. Since most scientific estimates are probabilistic determinations requiring reliable data, uncertainty can never be eliminated. Fortunately, some statistical methods will quantify the probable benefits of additional studies (e.g., Goodman 1986, Anderson et al. 1993, Taylor et al. 1993, Dakins et al. 1994). One frustrating denial of reality is that sufficient evidence can be gathered on complex problems so as to make the outcome of any policy decision certain.

Another denial of reality is that short-term economic growth is a key to sustainable use of the planet. The word 'development' is usually associated with growth, and growth, as used to describe the 'global marketplace', is not congruent with sustainable use (use without abuse) of a finite planet. Interdisciplinary teams will face great difficulties if words are used to obscure rather than enlighten. As Orwell (1949) noted, distortion of the meaning of words is driven by politics and economics. The integrity of interdisciplinary teams and the quest for sustainable use of the planet will depend 
upon using language to inform and to assure that actions correspond with statements. Good communication is the sine qua non of interdisciplinary teams since, without a well-understood common goal, the team becomes a façade. Goals must be set with deliberation that is coupled with contemplation and must engender a sense of community. Otherwise, the word 'team' is inappropriate-the term should not be applied to a collection of individuals who merely represent different disciplines.

Regrettably, given the funding problems of most academic institutions, interdisciplinary teams may be used to increase cash flow without offending other actual or potential sources of revenue. This possibility is further enhanced by the ranking of universities in the United States (and perhaps elsewhere) by the amount of research funding rather than by the degree to which they transform the prospects for bettering the human condition in sustainable ways. Research funding is easily counted, but is money the best measure of academic excellence?

\section{ILLUSTRATIVE HIGH PROFILE TEAM EFFORTS}

McNeill (2000) has superbly documented the scale and subtlety of environmental transformation in the 20th century, and persuasive evidence indicates that not only the rate of change but the spatial and temporal scales of these transformations are still increasing. In some way, the public, policymakers, politicians, news media, and, above all, the educational system must better understand the full implication of a world that will probably cross multiple ecological breakpoints or thresholds in the very near future. Worse yet, many of the processes affecting the rate of change are non-linear, and most are likely to be interactive, even synergistic. Non-linear 'surprises' may be a dominant theme of the 21st century.

In early May 2001, the U.S. government requested a 'fast-track' (short time frame) study to answer 14 specific questions concerning the science of climate change (Alberts 2000-2001). The 11-member committee produced 'Climate Change Science: An Analysis of Some Key Questions', which was released by the U.S. National Academy of Sciences in early June 2001. A total of 24 committee members and reviewers was involved with the report, 16 of whom were members of the National Academy of Sciences. Other 'high-profile' studies by the National Research Council (the operating arm of the U.S. National Academies of Science and Engineering) to be released in 2001 include: (1) arsenic in drinking water, (2) U.S. automobile fuel efficiency standards, and (3) stem cell research and human cloning (Alberts 2000-2001).
Politics is driven by economics, and economics can be strongly affected by environmental events (Egan 2001). A broad, general discussion of this topic is presented by Myers (1993). His concepts are the most likely source of motivation for politicians to make substantive efforts to minimize ecological calamities. However, most people will only act when they feel their lives or jobs are threatened, and then it may be too late. Clearly, environmental calamities will affect national security, but this situation is difficult for most people to visualize. However, positive signs point to the acceptance of interdisciplinary research by mainstream science (e.g., Wilson 1998, Gershon 2000). But, the rate of change appears glacial compared to the rate of change of forces that adversely affect the environment.

\section{ISOLATING MECHANISMS WITHIN DISCIPLINES}

Isolation is a powerful revolutionary force that discourages gene exchange and flow. It also impedes the open and free discussion of concepts in both academe and society as a whole. Isolating mechanisms in academic settings have been discussed elsewhere (Cairns 1988, 1992, 1993a,b, 1999a)—the major ones are (1) different tribal (disciplinary) rites of passage, (2) different tribal languages (disciplinary jargon), (3) geographic isolation (often housed in different buildings or different areas of the same building on campus), (4) professional advancement facilitated by publishing in specialized journals, and (5) professional meetings highly focused and often held in isolation from other disciplines. These barriers are not insurmountable, but an untenured assistant professor would do well to determine the views of the departmental tenure and promotion committee on the amount of time spent consorting with those in other tribes (i.e., disciplines).

On the other hand, most major problems of human society transcend the capabilities of any single discipline. Research aimed at solving these problems is a major source of extramural funding (i.e., grants and contracts). Slaughter \& Leslie (1997) note:

In this best case scenario, faculty have a greater role in governance, perhaps replacing middle level management. They capitalize on faculty initiative and develop small, fluid interdisciplinary units that are matched more closely with student demand and the external world. These units develop strategies for recruiting students and the dollars that follow them by creating programs that provide teaching, research opportunities for students, and research time for faculty to stay abreast of their fields, varying faculty work load across all members of a unit to meet overall needs. 
Another isolating mechanism is that policymakers, the general public, and, all too often, one's colleagues fail to understand fully what one is trying to communicate. A classic case is that of Gregor Mendel (Henig 2000). Mendel's life's work is a single, 44-page paper that was probably intended as the equivalent of a biology class reading for a group of 40 self-taught but enthusiastic naturalists. One wonders how long Einstein would have remained widely unknown had it not been for the British eclipse expeditions in 1919 that validated (through observation of the bending of starlight in the vicinity of a masssive body) Einstein's theory of relativity and made Einstein famous worldwide (Coles 1999). Many exemplary interdisciplinary studies will possibly similarly depend on sheer luck for being 'discovered'.

\section{FORMING AN INTERDISCIPLINARY TEAM}

Two basic choices are available in forming an interdisciplinary team: (1) a standing team that remains intact for a long period of time, although specialists may be replaced periodically and (2) a team formed by determining the disciplinary composite of each team and carefully considering the problem to be solved.

\section{Advantages and disadvantages of a standing team}

From 1948 through the first half of 1966, I was a member of an interdisciplinary, aquatic survey team in the Limnology Department of the Academy of Natural Sciences in Philadelphia. During this period, the team surveyed sections of hundreds of rivers and a few reservoirs, mostly in the United States and Canada but sometimes in South America (e.g., the Amazon River) and in Europe. The team consisted mostly of a group of taxonomic specialists (e.g., ichthyologist, entomologist, algologist, protozoologist, invertebrate zoologist, bacteriologist) who collected specimens and sent some (e.g., rotifers, bluegreen algae) to specialists and identified a large portion themselves. A water chemist was also on the team, and the team always interacted with sanitary engineers (now termed environmental engineers), waste treatment chemists, and the like-justifying the use of the word 'interdisciplinary', especially for that era.

Although there was some turnover within teams, there was an extended relationship among the members. Typically, an engineer or chemist from the sponsoring industry was accustomed to working with the team on a continuing basis, although the industrial plant sites (the most common sponsor) varied. The liaison person facilitated exchange of information with other disciplines. The team was quite efficient since each team member was familiar with the needs and working habits of the others, and the team spirit was usually remarkable.

However, since the team was entirely supported by grants and contracts, funding was usually sought that was congruent with the team's composition and capabilities. Consequently, there was no free and open exchange of ideas with a wide variety of disciplines that often occurs when the composition of the team is determined by the nature of the problem. Arguably, the worst case scenario is the temptation to accept, when the cash flow is inadequate, the contracts and grants for which the team is not well suited-there is an ethical responsibility to avoid such situations. On the positive side, having extramural funding as the sole source of funds gave team members a strong motive to cooperate with each other so as to increase the probability of acquiring funding.

\section{Advantages and disadvantages of a team assembled to solve a particular problem}

Since there is no 'one size fits all' interdisciplinary team composition, assembling a team with optimal composition for each particular problem makes sense. World-class research universities are probably best equipped for this task; however, the number of such institutions is small, and such problem-solving techniques are not their primary mission. Academic institutions whose primary mission is teaching have trouble providing release time for a number of faculty to participate in team activities, especially if the problem appears suddenly (e.g., an accidental spill of hazardous material) or is located at a substantial distance from the main campus. Since most faculty receive regular salaries, transitional funding (between grants) is not as big a problem as for institutions primarily dependent upon extramural funding. Another major advantage of assembling interdisciplinary teams in academic institutions is the availability of graduate and undergraduate help, as well as technicians. Their participation also gives them experience for involvement in future interdisciplinary teams. Some research organizations, consulting firms, government agencies, and the like also have a diverse array of disciplines and can form interdisciplinary teams that may include faculty members and students from academic institutions.

My own experience as director of a research center at Virginia Tech dealt with forming teams to solve a particular environmental problem. Much time was spent assembling a team, even as few as 6 people. Sometimes, department heads wanted the faculty member to participate on the interdisciplinary team without release time from other responsibilities, i.e., most department heads felt that a faculty member's 
primary loyalty was to the department. Institutions with a hierarchical structure based on the disciplines (vertical structure) are poorly equipped to cope with the horizontal problems of an interdisciplinary team. Departments traditionally deal with salary increases, promotions, space allocations, teaching load, committee service, and the like, not how to fairly and equitably judge a faculty member's participation on an interdisciplinary team.

\section{ETHICAL ISSUES IN A HIERARCHICAL ORGANIZATION}

Most organizations with a diverse array of disciplines rely on a hierarchical organization. Ethical concerns at each level should be considered. An illustrative list follows.

President, provost, or chief executive officer. Being a member of an effective interdisciplinary team is difficult and will require a substantial increase in working time, often without a corresponding increase in salary. An increase in motivation is essential, especially in a sustainability context such as restoring the integrity of the planet's biosphere. In Wilson's (1998) view, there is a consilience (literally 'leaping together') of the disciplines to create a new ecological design. In a sustainable use of the planet context, this design means making human society's relationship with natural systems harmonious, which in turn preserves and increases natural capital. However, administrations who employ lofty words to mask a hunger for increased cash flow will quickly dampen the team's zeal.

I had the good fortune to participate in an interdisciplinary team project as a graduate student, and this opportunity changed my life. Students are not customers or consumers, as the current business jargon would have it, but the people who will inspire the best in human capabilities and thought if leaders inspire ethical courage and creativity coupled with reason and wisdom. The inspiration of awe, reverence for life, compassion, responsibility, a sense of community, and the humility to recognize the importance of the contributions of other disciplines and colleagues might just result in sustainable use of the planet. This type of education will strengthen common humanity and better both the human condition and that of other life forms. The quest for compassion and wisdom is more important than the quest for money. The vision, not the money, should bond the members of an interdisciplinary team!

Deans and middle management. A cynic might well describe academe as a series of petty fiefdoms whose excesses are moderated to some degree by a higherranking overlord. However, interdisciplinary teams require administrative and intellectual orchestration. The dean (or middle management) must orchestrate the administrative portion of an interdisciplinary effort so that it does not impede but enhances the primary effortachieving a synthesis. This orchestration is particularly difficult when the team has members from 2 or more colleges. How should they assist a department chair in coping with a poor performer or in rewarding a stellar performance? Deans and middle management cannot ensure success, but they can easily ensure failure.

This activity is neither a diversion nor an unrewarding burden for a dean. Living sustainably will be the 'great work' of this century. Designing for sustainability requires redirection of human society's relationship with the biosphere and with the laws of nature. Even if deans and middle management are only interested in cash flow, sustainable use of the planet is where the action will be. Most important, creating a new covenant with nature can inspire the young to reconsider some words rarely used in the information age, such as compassion, responsibility, community, and the human condition.

Academic department chairperson. To paraphrase Gilbert and Sullivan, 'A department's chair's lot is not a happy one.' The department chair is the one who must make the ultimate allocation of resources or reallocation if no significant additional funds are received. A good case can be made for the involvement of public universities in the study of environment problems, particularly those affecting sustainable use of the planet. However, public universities have endured severe budget cuts from which many have not yet recovered. Finally, the team orchestrator (i.e., 'leader') is likely to select the most creative and highly motivated faculty from each discipline. Understandably, other faculty will not be enthusiastic about participating in interdisciplinary teams if it decreases departmental resources and increases their individual workload. Typically, the risks to a department chair of encouraging faculty and students to participate in interdisciplinary projects are abundantly clear, but the potential benefits and rewards are usually difficult to identify. In the light of these drawbacks, it is astonishing how much interdisciplinary work actually is accomplished.

Faculty. Given the circumstances already discussed, participation in interdisciplinary team activities means working longer hours with small change in equitable financial rewards. Twenty extra hours per week is common and 40 extra hour weeks are frequent. The wrath of one's colleagues in the home department is virtually assured, and most of one's colleagues want time spent within one's discipline.

On the positive side, the problems are fascinating and too complex for individual investigation. Interacting with other team members is a constant source of enlightenment. Obstacles to interdisciplinary activities are less formidable than they once were, but participa- 
tion in an interdisciplinary study is still far more difficult than it need be. The consilience paradigm, once it is more widely implemented, should markedly diminish the remaining obstacles.

\section{THE ULTIMATE ETHICAL PARADIGM}

Sustainable use of the planet requires a recognition that humans are a member species of the larger biological community and of future communities that will be affected by present actions. Integration of the social and natural sciences heralds a sustainable world where natural capital and ecosystem services are treasured and never exploited for personal wealth (Ehrlich 2000). Intelligence and creativity must be used to establish a mutualistic relationship with other life forms over large temporal and spatial spans. The first and foremost ethical responsibility is to restore and/or repair the damaged ecosystems of the world. The second is to decide how much of the planet is to be reserved for other species, how much for the human species, and how much should be shared in a harmonious and mutualistic fashion. A third major task is returning to the Greek meaning of the term economics as household management instead of managing for exponential growth and short-term financial gain. Fourth, humankind must not postpone precautionary strategies for such risks as global warming, endocrine disrupters, and the like. Finally, words like 'progress', which presently means technological progress, must be replaced with terms such as 'quality of life improvement' as a major guiding value. Reclaiming the common humanity of each individual and cherishing other life forms is a much more attractive future than traffic jams, road rage, decreasing civility, and the like.

Acknowledgements. I am indebted to Sue Rasmussen for transferring the first draft of this manuscript to the word processor. Darla Donald did her usual skillful job in editing the manuscript. I am indebted to Peter Leigh and Allan Dittmer for furnishing some very useful references. B. R. Niederlehner provided useful comments on the second draft. The Cairns Foundation paid for the processing costs.

\section{LITERATURE CITED}

Alberts B (2000-2001) From the president, letter to members. Nat Acad Sci 30(3):1

Anderson E, Deisler Jr PF, McCallum D, St. Hiliare C, Spitzer HL, Strauss H, Wilson JD, Zimmerman R (1993) Key issues in carcinogen risk assessment guidelines. Risk Analysis 13(4):379-382

Cairns Jr J (1988) Politics, economics, science-going beyond disciplinary boundaries to protect aquatic ecosystems. In: Evans M (ed) Toxic contaminants and ecosystem health: a
Great Lakes focus. J Wiley \& Sons, New York

Cairns Jr J (1992) Will integrative science develop with sufficient rapidity to mitigate global environmental degradation. Spec Sci Tech 15(1):54-59

Cairns Jr J (1993a). The intellectual electric fence. Annals of Earth XI(3):17-18

Cairns Jr J (1993b) Communication and status: the dilemma of an environmental scientist. Spec Sci Tech 16(3):163-170

Cairns Jr J (1997) Commentary: defining goals and conditions for a sustainable world. Environ Health Persp 105(11): $1164-1170$

Cairns Jr J (1999a) The diminished charge on the intellectual electric fence. The Social Contract IX(3):145-151

Cairns Jr J (1999b) Balancing ecological impairment and repair for sustainability. Hydrobiologia 416:77-83

Coles P (1999) Einstein and the total eclipse. Icon Books, Cambridge

Committee on Sustainable Water Supplies for the Middle East (1999) Water for the future: the West Bank and Gaza Strip, Israel, and Jordan. National Academy Press, Washington, DC

Dakins ME, Toll JE, Small MJ (1994) Risk-based environmental remediation: decision framework and role of uncertainty. Environ Toxicol Chem 13(12):1907-1915

Egan T (2001) Near vast bodies of water, land lies parched. New York Times, Aug12:1, 20-21

Ehrlich PR (2000) Human natures.Island Press, Washington DC

Gershon D (2000) Pushing the frontiers of interdisciplinary research: an idea whose time has come. Nature 404: 313-315

Goodman J (1986) On criteria of insignificant differences between two risks. Risk Analysis 6(2):235-244

Hawken P, Lovins, A Lovins H (1999) Natural capitalism: creating the next Industrial Revolution. Little, Brown \& Co. New York

Henig RM (2000) The monk in the garden. Houghton Mifflin, New York

Lemons J (ed) (1996) Scientific uncertainty. Blackwell, Cambridge, MA

McNeill JR (2000) Something new under the sun: an environmental history of the twentieth-century world. WW Norton, London

Murphy D (2001a) 'Good wood' labeling: can it save Asia's tropical forests? Christian Sci Monitor Aug 23:1,12-13

Murphy D (2001b) The quest for certifiably eco-friendly lumber. Christian Sci Monitor Oct 23:13

Myers N (1993) Ultimate security: the environmental basis of political stability. WW Norton, New York

Myers N with Kent JV (1998) Perverse subsidies: tax \$s undercutting our economies and environment alike. International Institute for Sustainable Development, Winnipeg, Manitoba

Orwell G (1949) 1984. Harcourt, Brace, New York

Raffensperger C, Tickner JA (1999) Protecting public health and the environment: implementing the precautionary principle. Island Press, Washington, DC

Slaughter S, Leslie LL (1997) Academic capitalism. Johns Hopkins University Press, Baltimore

Taylor AC, Evans JS, McKone TE (1993) The value of animal test information in environmental control decisions. Risk Analysis 13(4):403-412

Wackernagel M, Rees W (1996) Our ecological footprint. New Society Publishers, Gabriola Island, British Columbia

Wilson EO (1998) Consilience: the unity of knowledge. Random House, New York 